\title{
Intermittent or sustained systemic inflammation and the preterm brain
}

\author{
Olaf Dammann ${ }^{1-3}$ and Alan Leviton ${ }^{4}$
}

Exposure to perinatal infection and inflammation is associated with an increased risk for neonatal brain damage and developmental disabilities. In this integrated mechanism review, we discuss evidence in support of the contention that the preterm newborn is capable of intermittent or sustained systemic inflammation (ISSI), which appears to contribute more to adverse neurodevelopmental outcomes in preterm infants than does shorter duration inflammation.

$\mathrm{T}$ he concept that noninfectious inflammatory stimuli contribute to perinatal brain damage dates back four decades (1). More than $15 \mathrm{y}$ ago, this concept was expanded to help explain the relationship between contributors to preterm birth and perinatal brain damage $(2,3)$.

Since then, the major new concept has been the role of sustained inflammation (4). The recent abundance of publications relevant to intermittent or sustained systemic inflammation (ISSI) prompts this update of recent progress.

\section{ISSI}

\section{What Is Systemic Inflammation?}

Although many infections are thought to be characterized by inflammation localized to a tissue or organ, some clinicians want to see leukocytosis before they make a diagnosis of appendicitis (5). The increase in number of immune cells and/or the increased concentration of inflammation-related proteins (e.g., C-reactive protein and proinflammatory cytokines) in the circulation is deemed evidence of systemic inflammation (6).

\section{What Is Chronic Systemic Inflammation?}

A rapidly mounted systemic inflammatory response can be an effective defense against microbial invasion and should finally resolve (7). Failure of inflammation-resolution processes, however, leads to dysregulated and prolonged inflammation, which can damage organs and contribute to the development in adults of malignancies, chronic lung disease, rheumatoid arthritis, type 2 diabetes mellitus, heart disease, and such neurological disorders as stroke, Parkinson's disease, Alzheimer's disease, multiple sclerosis, and a diverse group of other neurodegenerative diseases (8).

\section{What Is ISSI?}

We currently do not know if the systemic inflammation in very preterm newborns that predicts brain damage is intermittent or sustained. Until that knowledge becomes available, we consider it appropriate to use the term "ISSI" for this brain damage risk factor or indicator of other risk factors.

Both adjectives, intermittent and sustained, allow for the inflammation to eventually resolve. Some authors do not hesitate to eliminate this possibility when using the word "persistent" in describing among surgical patients what they call PICS, persistent inflammation, immunosuppression, and catabolism syndrome (9).

Some of what follows pertains to sustained inflammation in the brain and not necessarily in the circulation. We cite this literature in support of the concept of sustained inflammation and caution drawing inferences to what might be occurring in the blood when circulating indicators of systemic inflammation have not been measured.

\section{ISSI and Secondary Brain Damage}

Closed head trauma can be followed by a prominent neuroinflammatory response (10). Although this might serve to assist in removal of debris and initiate repair, the possibility has also been raised that this phenomenon might contribute to ongoing "secondary" damage (11).

This phenomenon of secondary damage does not explain the systemic response that sometimes accompanies brain damage. This inflammation in the blood is most likely a reflection of inflammation that "spilled over" from the brain, or inflammation-provoking signals sent from the brain to the liver and the peripheral immune system (12). This inflammation in the blood following brain damage might be merely an indicator of the damage already done. On the other hand, the systemic inflammation might contribute to "secondary damage". A systemic anti-inflammatory approach to reducing secondary damage appears promising (13).

\section{ISSI and Tertiary Brain Damage}

Tertiary brain damage is defined as "injury caused by longpersisting processes following brain insult that worsen 


\section{Sustained inflammation}

outcome, predispose to further injury, or prevent repair/regeneration" $(11,14)$. One possible example comes from the observation that years after preterm birth, children who developed cerebral palsy had elevated tumor necrosis factor (TNF)- $\alpha$ concentrations in their plasma (15).

Schizophrenia and some other chronic psychotic disorders have inflammatory characteristics (16). Treatment with antiinflammatory compounds appears to reduce the severity of some symptoms.

These observations, too, can be viewed as support for the concept of tertiary inflammatory damage. They go beyond, though, holding out the promise that systemic anti-inflammatory therapy might reduce the severity of symptoms of disorders with on-going inflammation. Because autism has some of the same inflammatory characteristics as schizophrenia (17), the possibility exists that systemic anti-inflammatory therapy might prove helpful here, too.

\section{ISSI and the Developing Brain-Animal Studies}

Thirty-five days after a local, apparently noninflammatory set of brain-damaging stimuli, immature rats' microglia/macrophages, astroglia, and CD4 lymphocytes in the brain remained activated (18). Giving lipopolysaccharide, a powerful inflammatory stimulus, to pregnant rats is followed by apoptosis of brain cells in their newborn a week after birth (19). Three months following a hypoxic-ischemic insult to the brain of mouse pups, activated T lymphocytes were still present in the damaged hemisphere (20).

\section{ISSI and the Developing Brain-Human Studies}

Elevated concentrations of inflammation-related proteins in the circulation on two separate occasions a week apart shortly after preterm birth provide information about an increased risk of microcephaly more than 2 y later (21). As mentioned above, school-aged children with cerebral palsy have higher TNF plasma levels than controls and their monocytes exhibit a more vigorous TNF response to lipopolysaccharide stimulation than monocytes from controls (15). In addition, the presence of astrocyte damage marker S100B in the systemic circulation of children with cerebral palsy suggests that the disease process might be ongoing/sustained as well (22). Elevated levels of inflammation-related proteins in blood collected on both postnatal days 7 and 14 are associated with impaired mental and motor development at age $2 \mathrm{y}$ (23). ISSI also plays a prominent role in one framework proposed for the etiology of schizophrenia and autism (17).

\section{MECHANISMS}

In this section, we try to answer the question, "What perpetuates inflammation to make it chronic?" (Figure 1). One possibility is that the inflammatory stimulus persists. A second is that the resolution of inflammation is hampered. Third, preterm newborns have developmentally regulated characteristics that allow reinforcement loops to sustain systemic inflammation (24). Fourth, positive feedback loops between innate and adaptive immune systems might perpetuate the inflammatory

\section{Integrated Mechanism Review}

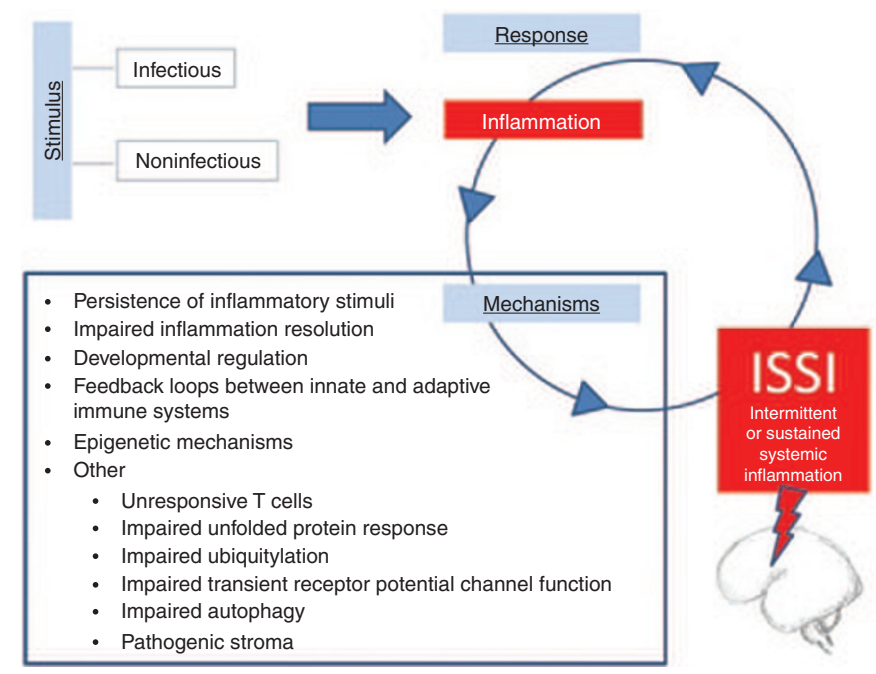

Figure 1. Proposed list of candidate mechanisms linking infectious and noninfectious stimuli, the initial inflammatory response, and subsequent intermittent or sustained systemic inflammation (ISSI).

responses (25). A fifth candidate mechanism involves epigenetics. This section ends with a list of multiple miscellaneous but not mutually exclusive possibilities.

\section{Persistence of Inflammatory Stimuli}

In the preterm newborn, assisted (i.e., mechanical) ventilation might be the most common prolonged/continued stimulus for systemic inflammation (26). One explanation for this link between assisted ventilation and systemic inflammation invokes barotrauma provocation of the local synthesis of inflammation-associated proteins, followed by translocation of some of these proteins from the lung to the circulation. In support of this interpretation is the observation that strategies that reduce ventilator-induced lung injury appear to reduce systemic inflammation in newborns (27). The presence of endotoxin in tracheal aspirates from mechanically ventilated newborns accompanied by inflammation-associated proteins suggests that some of the inflammation associated with assisted ventilation is the consequence of infection (28).

The other common systemic inflammation-provoking exposure among very preterm newborns is bacteremia $(29,30)$. The reasons for their propensity to become bacteremic are complex, but include exposure to maternal organisms, need for assisted ventilation, fragile skin, impaired $\mathrm{T}(\mathrm{H}) 17$-polarizing cytokine production, and deficient expression of complement, as well as a deficiency of antimicrobial proteins and peptides (31). The acquisition of gut microbiota at the time the intestinal epithelium is immature might contribute to the translocation of bacteria from the gut to the adjacent blood vessels and their blood contents (32).

Toll-like receptors (TLRs) are pattern recognition receptors that can recognize pathogen-associated molecular patterns (including bacterial components), as well as endogenous substances released during/following injury and inflammation (including oxidized phospholipids, oxidized low-density 


\section{Integrated Mechanism Review}

lipoproteins, $\beta$-defensin, high-mobility group protein 1 , and heat shock proteins) (33). When these activate TLR-2 or TLR4 , the result is induction of the transcription factor nuclear factor- $\kappa \mathrm{B}$, which then promotes the synthesis and release of such inflammation-related proteins as interleukin (IL)-6 and TNF- $\alpha$. The resulting inflammation and injury can thereby promote chronic inflammation.

\section{Inflammation Resolution}

The normal inflammatory response includes components that contribute to the termination of the inflammatory response (34). This resolution of inflammation is tightly regulated by anti-inflammatory proteins, such as IL-4, IL-5, IL-10, and IL-13 (35) and proresolving proteins, especially transforming growth factor- $\beta$ (36). Preterm newborns appear to have a paucity of some of these proteins $(37,38)$.

Other endogenous products of inflammation contribute to resolution. Among these are a variety of lipid mediators derived from arachidonic acid in the plasma membrane, including prostaglandins, lipoxins, and resolvins. We still do not know how capable the preterm newborn is in synthesizing these lipid-based inflammation-resolution promoters.

A subset of neutrophils from preterm newborns when exposed to inflammatory stimuli appears to be relatively resistant to apoptosis (39). The continued presence of such cells in term newborns (40) can contribute to continued (i.e., subacute and/or chronic) inflammation. Indeed, the pool of such apoptosis-resistant cells appears to be relatively larger in newborns than adults (41). Here, too, we do not know how much the prolonged presence of these apoptotic-resistant cells enhances the probability of ISSI.

\section{Developmental Regulation}

Data from observational and experimental studies document that, once initiated, the fetal/neonatal inflammatory response can be sustained for long intervals (4). Phenomena that vary with gestational age are identified as "developmentally regulated." Several components of the inflammatory response of preterm newborns that are deemed "developmentally regulated" might account for some of the inflammatory hyperresponsiveness and persistence that has been documented.

Following an intravenous inflammatory stimulus (i.e., lipopolysaccharide), healthy young adults volunteers have TNF- $\alpha$ and IL- 6 concentrations that peak at about 2 to $2 \frac{1}{2}$ hours and return to baseline within $12 \mathrm{~h}$ (42). In preterm newborns, however, some indicators of systemic inflammation (proinflammatory cytokines) are elevated after birth much longer than would be expected based on their half-life in adults $(43,44)$. We still do not know the half-life of inflammation-related proteins in preterm newborns. Consequently, we do not yet know if the sustained inflammation reflects nothing more than a developmentally regulated very prolonged catabolic process.

Compared to their counterparts at term, preterm rats and humans appear to have limited ability to synthesize proteins with anti-inflammatory characteristics $(45,46)$. Despite this weak anti-inflammatory capability, very preterm newborns

\section{Dammann and Leviton}

appear to be capable of a more vigorous systemic inflammatory response than gestationally older newborns $(47,48)$. The result is a propensity to a proinflammatory imbalance of proteins that is not readily eliminated.

\section{Positive Feedback Loops Between Innate and Adaptive Immune Systems}

In adults, the innate and adaptive immune systems reinforce each other (49). Support has been provided for the possibility that the innate and adaptive immune systems reinforce each other in the very preterm newborn, thereby prolonging the inflammation and increasing the likelihood of brain damage (25). Part of this phenomenon might be due to an insufficient number of $\mathrm{T}$ cells that leads to "uncontrolled' inflammation (50). In addition, proinflammatory cytokines and other aspects of the inflammatory environment have the potential to diminish the response of effector $\mathrm{T}$ cells to regulation (51).

\section{Epigenetic Mechanisms}

Epigenetic processes modify gene expression and/or cell phenotype without altering the genomic DNA (11). Many of these pack/unpack (i.e., tighten/loosen the bonds of) chromatin. For a gene to be transcribed, it has to be "unpacked" from the chromatin (52). In turn, a gene can be silenced by "packing" the chromatin. The two mechanisms most often involved in transforming the chromatin alter nucleosomal histones, or micro(noncoding)-RNA expression. DNA methylation is another epigenetic mechanism.

Normal acute systemic inflammation follows a set pattern beginning with an initiation (proinflammatory) phase, rapidly followed by an adaptive (anti-inflammatory) phase, and finally a resolution (restoration of homeostasis) phase (7). These phase shifts are accompanied by changes in gene expression, some due in part to epigenetic processes. The shift from a proinflammatory to an anti-inflammatory state, for example, is accompanied by the repression of some genes and the activation of others (53).

Inflammation-stimulated cells undergo extensive transcriptional reprogramming mediated, in part, by inducing histone deacetylases (54) and by enhancing methylation and/or acetylation at specific histone proteins (55).

Just as chromatin reorganization (including histone deacetylation) contributes to inflammation opening access to promoters of acute proinflammatory genes, subsequent chromatin reorganization (including histone acetylation), tends to close access to these promoters of acute proinflammatory genes, thereby facilitating the transition to the anti-inflammatory state (56). Some histone deacetylases, however, put a brake on the propensity to resolve inflammation (57), while other histone deacetylases appear to promote inflammatory gene expression in response to inflammatory stimuli (58). The net effect of histone deacetylation, however, is inflammation promotion (59).

Some micro-RNA influence inflammation, and inflammation, in turn, influences the biogenesis of some of these, as well as other micro-RNAs (60). Some of these micro-RNAs 


\section{Sustained inflammation}

dampen the inflammatory process, while others potentiate the immune response.

\section{Miscellaneous Additional Mechanisms}

Ongoing tissue destruction leads to continued inflammation. Necrosis of any cells, including brain cells, leads to the release of cellular proteins and other nuclear/cell contents. Some of these function as damage-associated molecular patterns that, once outside the cell, can induce noninfection-associated immune responses (61). The result is continued inflammation. Some of the damage-associated molecular patterns generated during traumatic injury leak into the systemic circulation (62). If the damage-associated molecular patterns released by brain damage within the blood-brain barrier of preterm newborns leak into the systemic circulation and contribute to ISSI, might the developing brain be less able than the mature brain to contain damageassociated molecular patterns within the blood-brain barrier?

Inflammatory phenomena induce endoplasmic reticulum stress, which, in turn, leads to the unfolded protein response, which is followed by even more inflammation (63). The relationship between the ubiquitin proteasome system and inflammation is complex (64). Normally, the induction of proteasomes clears accumulating misfolded proteins, thereby minimizing continued inflammation. Consequently, impairments of ubiquitylation can contribute to continuing inflammation. Products of inflammation acting on transient receptor potential channels can promote the release of substances that promote further inflammation (65). Autophagy is an intracellular mechanism that removes damaged or unused cell components, including inflammatory stimuli (66). Because impairments of autophagy allow some of these to remain, they allow the inflammation to continue. Finally, stroma includes fibroblasts, as well as blood and lymphatic vessels. "The stroma, formerly considered the theatrical stage of the inflammatory process, has acquired, in recent years the role of director of the immune response, regulating the process of leukocyte recruitment, organization of leukocytes within the tissue and exit via the escape route of the lymphatic endothelium" (67). Continued inflammation can result in the acquisition by stromal cells of novel features that can contribute to the perpetuation of inflammation.

\section{Intervention Design}

Multiple potential anti-inflammatory and/or immunomodulatory intervention schemes are conceivable with the perinatal brain in mind $(68,69)$. If ISSI indeed contributes to brain damage in the preterm newborn over an extended time period, a wide window of opportunity would open for such intervention (4), perhaps even after the onset of the initiator of ISSI. Targeting the mechanisms of ISSI discussed above seems to be a reasonable strategy when thinking about future interventions to curb its adverse effects.

\section{CONCLUSION}

Intermittent or sustained inflammation appears to characterize a large number of disorders of different organs. Here, we focus on the newborn brain, especially the brain of infants

\section{Integrated Mechanism Review}

born months before term, and offer evidence that the very preterm newborn has the capacity to sustain inflammation, thereby increasing the risk of brain damage.

\section{STATEMENT OF FINANCIAL SUPPORT}

The authors received funding from the National Institute of Neurological Disorders and Stroke, National Institutes of Health (NIH, Bethesda, MD; grants 5U01NS040069-05; 2R01NS040069-06A2), the National Eye Institute (NIH; grant 1-R01-EY021820-01A1), and the National Institute of Child Health and Human Development (NIH; grant 5P30HD018655-28).

Disclosure: The authors have no financial ties to disclose.

\section{REFERENCES}

1. Leviton A, Gilles FH. An epidemiologic study of perinatal telencephalic leucoencephalopathy in an autopsy population. J Neurol Sci 1973;18:53-66.

2. Leviton A. Preterm birth and cerebral palsy: is tumor necrosis factor the missing link? Dev Med Child Neurol 1993;35:553-8.

3. Dammann O, Leviton A. Maternal intrauterine infection, cytokines, and brain damage in the preterm newborn. Pediatr Res 1997;42:1-8.

4. Dammann O. Persistent neuro-inflammation in cerebral palsy: a therapeutic window of opportunity? Acta Paediatr 2007;96:6-7.

5. Kulik DM, Uleryk EM, Maguire JL. Does this child have appendicitis? A systematic review of clinical prediction rules for children with acute abdominal pain. J Clin Epidemiol 2013;66:95-104.

6. Jaffer U, Wade RG, Gourlay T. Cytokines in the systemic inflammatory response syndrome: a review. HSR Proc Intensive Care Cardiovasc Anesth 2010;2:161-75.

7. McCall CE, El Gazzar M, Liu T, Vachharajani V, Yoza B. Epigenetics, bioenergetics, and microRNA coordinate gene-specific reprogramming during acute systemic inflammation. J Leukoc Biol 2011;90:439-46.

8. Tabas I, Glass CK. Anti-inflammatory therapy in chronic disease: challenges and opportunities. Science 2013;339:166-72.

9. Gentile LF, Cuenca AG, Efron PA, et al. Persistent inflammation and immunosuppression: a common syndrome and new horizon for surgical intensive care. J Trauma Acute Care Surg 2012;72:1491-501.

10. Schmidt OI, Heyde CE, Ertel W, Stahel PF. Closed head injury-an inflammatory disease? Brain Res Brain Res Rev 2005;48:388-99.

11. Thornton C, Rousset CI, Kichev A, et al. Molecular mechanisms of neonatal brain injury. Neurol Res Int 2012;2012:506320.

12. Anthony DC, Couch Y, Losey P, Evans MC. The systemic response to brain injury and disease. Brain Behav Immun 2012;26:534-40.

13. d'Avila JC, Lam TI, Bingham D, et al. Microglial activation induced by brain trauma is suppressed by post-injury treatment with a PARP inhibitor. J Neuroinflammation 2012;9:31.

14. Fleiss B, Gressens P. Tertiary mechanisms of brain damage: a new hope for treatment of cerebral palsy? Lancet Neurol 2012;11:556-66.

15. Lin CY, Chang YC, Wang ST, Lee TY, Lin CF, Huang CC. Altered inflammatory responses in preterm children with cerebral palsy. Ann Neurol 2010;68:204-12.

16. Suvisaari J, Mantere O. Inflammation theories in psychotic disorders: a critical review. Infect Disord Drug Targets 2013;13:59-70.

17. Meyer U, Feldon J, Dammann O. Schizophrenia and autism: both shared and disorder-specific pathogenesis via perinatal inflammation? Pediatr Res 2011;69(5 Pt 2):26R-33R.

18. Bona E, Andersson AL, Blomgren $\mathrm{K}$, et al. Chemokine and inflammatory cell response to hypoxia-ischemia in immature rats. Pediatr Res 1999;45(4 Pt 1):500-9.

19. Rousset CI, Chalon S, Cantagrel S, et al. Maternal exposure to LPS induces hypomyelination in the internal capsule and programmed cell death in the deep gray matter in newborn rats. Pediatr Res 2006;59:428-33.

20. Winerdal M, Winerdal ME, Kinn J, Urmaliya V, Winqvist O, Adén U. Long lasting local and systemic inflammation after cerebral hypoxic ischemia in newborn mice. PLoS One 2012;7:e36422.

21. Leviton A, Kuban KC, Allred EN, Fichorova RN, O'Shea TM, Paneth N; ELGAN Study Investigators. Early postnatal blood concentrations of inflammation-related proteins and microcephaly two years later in infants born before the $28^{\text {th }}$ post-menstrual week. Early Hum Dev 2011;87:325-30. 
22. Park ES, Park CI, Choi KS, Choi IH, Shin JS. Over-expression of S100B protein in children with cerebral palsy or delayed development. Brain Dev 2004;26:190-6.

23. O'Shea TM, Allred EN, Kuban KC, et al.; Extremely Low Gestational Age Newborn (ELGAN) Study Investigators. Elevated concentrations of inflammation-related proteins in postnatal blood predict severe developmental delay at 2 years of age in extremely preterm infants. J Pediatr 2012;160:395-401.e4.

24. Leviton A, Fichorova R, Yamamoto Y, et al. Inflammation-related proteins in the blood of extremely low gestational age newborns. The contribution of inflammation to the appearance of developmental regulation. Cytokine 2011;53:66-73.

25. Leviton A, Dammann O, Durum SK. The adaptive immune response in neonatal cerebral white matter damage. Ann Neurol 2005;58:821-8.

26. Bose CL, Laughon MM, Allred EN, et al.; ELGAN Study Investigators. Systemic inflammation associated with mechanical ventilation among extremely preterm infants. Cytokine 2013;61:315-22.

27. Capoluongo E, Vento G, Santonocito C, et al. Comparison of serum levels of seven cytokines in premature newborns undergoing different ventilatory procedures: high frequency oscillatory ventilation or synchronized intermittent mandatory ventilation. Eur Cytokine Netw 2005;16:199-205.

28. Nathe KE, Mancuso CJ, Parad R, et al. Innate immune activation in neonatal tracheal aspirates suggests endotoxin-driven inflammation. Pediatr Res 2012;72:203-11.

29. Sood BG, Shankaran S, Schelonka RL, et al.; Eunice Kennedy Shriver National Institute of Child Health and Human Development Neonatal Research Network. Cytokine profiles of preterm neonates with fungal and bacterial sepsis. Pediatr Res 2012;72:212-20.

30. Leviton A, O'Shea TM, Bednarek FJ, Allred EN, Fichorova RN, Dammann O; ELGAN Study Investigators. Systemic responses of preterm newborns with presumed or documented bacteraemia. Acta Paediatr 2012;101:355-9.

31. Cuenca AG, Wynn JL, Moldawer LL, Levy O. Role of innate immunity in neonatal infection. Am J Perinatol 2013;30:105-12.

32. Sherman MP. New concepts of microbial translocation in the neonatal intestine: mechanisms and prevention. Clin Perinatol 2010;37:565-79.

33. Lucas K, Maes M. Role of the Toll Like receptor (TLR) radical cycle in chronic inflammation: possible treatments targeting the TLR4 Pathway. Mol Neurobiol 2013;48:190-204.

34. Ariel A, Timor O. Hanging in the balance: endogenous anti-inflammatory mechanisms in tissue repair and fibrosis. J Pathol 2013;229:250-63.

35. Opal SM, DePalo VA. Anti-inflammatory cytokines. Chest 2000;117:1162-72.

36. Yang YC, Zhang N, Van Crombruggen K, Hu GH, Hong SL, Bachert C. Transforming growth factor-betal in inflammatory airway disease: a key for understanding inflammation and remodeling. Allergy 2012;67:1193-202.

37. Jones CA, Cayabyab RG, Kwong KY, et al. Undetectable interleukin (IL)-10 and persistent IL-8 expression early in hyaline membrane disease: a possible developmental basis for the predisposition to chronic lung inflammation in preterm newborns. Pediatr Res 1996;39:966-75.

38. Blahnik MJ, Ramanathan R, Riley CR, Minoo P. Lipopolysaccharideinduced tumor necrosis factor-alpha and IL-10 production by lung macrophages from preterm and term neonates. Pediatr Res 2001;50:726-31.

39. Kotecha S, Mildner RJ, Prince LR, et al. The role of neutrophil apoptosis in the resolution of acute lung injury in newborn infants. Thorax 2003;58:961-7.

40. Nguyen CN, Schnulle PM, Chegini N, Luo X, Koenig JM. Neonatal neutrophils with prolonged survival secrete mediators associated with chronic inflammation. Neonatology 2010;98:341-7.

41. Hanna N, Vasquez P, Pham P, et al. Mechanisms underlying reduced apoptosis in neonatal neutrophils. Pediatr Res 2005;57:56-62.

42. Vedder H, Schreiber W, Yassouridis A, Gudewill S, Galanos C, Pollmächer T. Dose-dependence of bacterial lipopolysaccharide (LPS) effects on peak response and time course of the immune-endocrine host response in humans. Inflamm Res 1999;48:67-74.

43. Dammann O, Phillips TM, Allred EN, et al.; ELGAN STUDY INVESTIGATORS. Mediators of fetal inflammation in extremely low gestational age newborns. Cytokine 2001;13:234-9.

44. Skogstrand K, Hougaard DM, Schendel DE, Bent NP, Svaerke C, Thorsen P. Association of preterm birth with sustained postnatal inflammatory response. Obstet Gynecol 2008;111:1118-28.
45. Brochu ME, Girard S, Lavoie K, Sébire G. Developmental regulation of the neuroinflammatory responses to LPS and/or hypoxia-ischemia between preterm and term neonates: An experimental study. J Neuroinflammation 2011;8:55.

46. Gille C, Dreschers S, Leiber A, et al. The CD95/CD95L pathway is involved in phagocytosis-induced cell death of monocytes and may account for sustained inflammation in neonates. Pediatr Res 2013;73(4 Pt 1):402-8.

47. Wynn JL, Levy O. Role of innate host defenses in susceptibility to earlyonset neonatal sepsis. Clin Perinatol 2010;37:307-37.

48. Thornton NL, Cody MJ, Yost CC. Toll-like receptor $\frac{1}{2}$ stimulation induces elevated interleukin-8 secretion in polymorphonuclear leukocytes isolated from preterm and term newborn infants. Neonatology 2012;101:140-6.

49. Raymond T, Schaller M, Hogaboam CM, Lukacs NW, Rochford R, Kunkel SL. Toll-like receptors, Notch ligands, and cytokines drive the chronicity of lung inflammation. Proc Am Thorac Soc 2007;4:635-41.

50. Zhao J, Yang X, Auh SL, Kim KD, Tang H, Fu YX. Do adaptive immune cells suppress or activate innate immunity? Trends Immunol 2009;30:8-12.

51. Wehrens EJ, Prakken BJ, van Wijk F. T cells out of control-impaired immune regulation in the inflamed joint. Nat Rev Rheumatol 2013;9:34-42.

52. Foster SL, Medzhitov R. Gene-specific control of the TLR-induced inflammatory response. Clin Immunol 2009;130:7-15.

53. Shnyra A, Brewington R, Alipio A, Amura C, Morrison DC. Reprogramming of lipopolysaccharide-primed macrophages is controlled by a counterbalanced production of IL-10 and IL-12. J Immunol 1998;160:3729-36.

54. Aung HT, Schroder K, Himes SR, et al. LPS regulates proinflammatory gene expression in macrophages by altering histone deacetylase expression. FASEB J 2006;20:1315-27.

55. Zhu H, Shan L, Schiller PW, Mai A, Peng T. Histone deacetylase-3 activation promotes tumor necrosis factor-alpha (TNF-alpha) expression in cardiomyocytes during lipopolysaccharide stimulation. J Biol Chem 2010;285:9429-36.

56. Natoli G. Tuning up inflammation: how DNA sequence and chromatin organization control the induction of inflammatory genes by NF-kappaB. FEBS Lett 2006;580:2843-9.

57. Mullican SE, Gaddis CA, Alenghat T, et al. Histone deacetylase 3 is an epigenomic brake in macrophage alternative activation. Genes Dev 2011;25:2480-8.

58. Chen X, Barozzi I, Termanini A, et al. Requirement for the histone deacetylase Hdac3 for the inflammatory gene expression program in macrophages. Proc Natl Acad Sci U S A 2012;109:E2865-74.

59. Shakespear MR, Halili MA, Irvine KM, Fairlie DP, Sweet MJ. Histone deacetylases as regulators of inflammation and immunity. Trends Immunol 2011;32:335-43.

60. Boldin MP, Baltimore D. MicroRNAs, new effectors and regulators of NF-KB. Immunol Rev 2012;246:205-20.

61. Kaczmarek A, Vandenabeele P, Krysko DV. Necroptosis: the release of damage-associated molecular patterns and its physiological relevance. Immunity 2013;38:209-23.

62. Pittman K, Kubes P. Damage-associated molecular patterns control neutrophil recruitment. J Innate Immun 2013;5:315-23.

63. Bueter W, Dammann O, Leviton A. Endoplasmic reticulum stress, inflammation, and perinatal brain damage. Pediatr Res 2009;66:487-94.

64. Voigt A, Rahnefeld A, Kloetzel PM, Krüger E. Cytokine-induced oxidative stress in cardiac inflammation and heart failure-how the ubiquitin proteasome system targets this vicious cycle. Front Physiol 2013;4:42.

65. Palazzo E, Rossi F, de Novellis V, Maione S. Endogenous modulators of TRP channels. Curr Top Med Chem 2013;13:398-407.

66. Bendix I, Schulze C, Haefen Cv, et al. Erythropoietin modulates autophagy signaling in the developing rat brain in an in vivo model of oxygen-toxicity. Int J Mol Sci 2012;13:12939-51.

67. Barone F, Nayar S, Buckley CD. The role of non-hematopoietic stromal cells in the persistence of inflammation. Front Immunol 2012;3:416.

68. Wolfberg AJ, Dammann O, Gressens P. Anti-inflammatory and immunomodulatory strategies to protect the perinatal brain. Semin Fetal Neonatal Med 2007;12:296-302.

69. Degos V, Loron G, Mantz J, Gressens P. Neuroprotective strategies for the neonatal brain. Anesth Analg 2008;106:1670-80. 